\title{
NUMERICAL INVESTIGATION OF A PHYSICALLY NONLINEAR PROBLEM OF THE LONGITUDINAL BENDING OF THE SANDWICH PLATE WITH A TRANSVERSAL-SOFT CORE
}

\author{
I.B. Badriev ${ }^{1}$, M.V. Makarov ${ }^{1,2}$, V.N. Paimushin ${ }^{1,2}$ \\ ${ }^{1}$ Kazan Federal University, Kazan, Russian Federation \\ ${ }^{2}$ Kazan National Research Technical University, Kazan, Russian Federation
}

\section{ARTICLE INFO}

Received: 14.02 .2017

Accepted: 15.03 .2017

Published: 25.12.2018

\section{Keywords:}

mathematical simulation, sandwich plate, transversely soft core, physically nonlinear problem, generalized statement, solvability theorem, convergence theorem, iterative method, numerical experiment.

\begin{abstract}
In this paper, a numerical investigation of a physically nonlinear problem of the longitudinal bending of an infinitely long sandwich plate with a transversal-soft core is carried out. We assume that in the right face section the edges of the carrier layers are clamped and there is no adhesive joint of the core with the support element, in the left face section the edges of the carrier layers of the plates are hinge supported on a completely rigid in the transverse direction diaphragms, glued with the end section of the core. The problem is considered in the one-dimensional geometrically nonlinear statement. It is assumed that the relationship between the tangential stress and strain shear corresponds to the ideal elastic-plastic models, i.e., the tangential stress modules in the core do not exceed a certain limiting value. This condition means the prevention of the structural failure and corresponds to an account of the physical nonlinearity in the core material by the ideal elasticplastic model. The generalized statement is formulated as a problem of finding a saddle point of the Lagrange generalized functional. Lagrange functional properties are investigated. Its convexity, lower semicontinuity and coercivity on the basic variables (displacements of the points of the middle surface of the carrier layers), the concavity, upper semicontinuity and anti-coercivity on the Lagrange multipliers (tangential stresses in the core) are established. It made it possible to use the general theory of the existence of saddle points to prove the existence and uniqueness theorem. To solve the problem the two-layer iterative Uzawa method is proposed, each step of which is reduced to the solving of the linear elasticity problem and finding the projection onto the convex closed set. We have established the convergence of the method. By using the software package developed in Matlab environment, the numerical experiments for a model problem have been carried out. The analysis of the results is made. The numerical results correspond to the physical picture.
\end{abstract}

@ Ildar B. Badriev - Doctor of Physical and Mathematical Sciences, Professor, e-mail: ildar.badriev1@mail.ru

Maksim V. Makarov - Junior Researcher, e-mail: makarovmaksim@mail.ru

Vitaly N. Paimushin - Doctor of Physical and Mathematical Sciences, Professor, e-mail: vpajmushin @mail.ru 


\section{Introduction}

Increase of efficiency of modern aerospace engineering is inextricably connected with search for and implementtation of new design and process solutions. These solutions are significantly related to application of composite materials [1-6]. One of important areas in shell-type structures (bodies of missiles, ships, fuselages and wings of aircraft and helicopters, as well as other items) is creation and expanding application of multilayer [7-12], sandwich structures the elements of which consist of two carrying layers and the light core between them [13-21].

Efficiency of sandwich structures is primarily related to their high relative stiffness and strength. Carrying layers supported by the core take high compression stresses. Owing to high local and total bending and torsional stiffness, less amount of ribs, frames and other support elements is required. Higher stiffness of such structures ensure preservation of aerodynamic performance. Owing to uniform reinforcement of carrying layers with the core and to the lack of stress raisers, life time of such structures increases. However, they are more poorly customized for transmission of forces (especially, concentrated ones) from one element to another. In this regard, one of the main questions of sandwich structures design is rational choice of connections to other elements.

This paper studies the geometrically linear and physically nonlinear problem of longitudinal bending of the sandwich plate with the transversely soft core (refer to Fig. 1, a). The term "transversely soft core" has been used in the mechanics of sandwich and multilayer structures for a long time. According to the classification of Bolotin V.V. [22], the class of transversely soft cores comprises of cores where tangential components of the stress tensor are small compared to other components. Configuration of loading and fastening of the plate considered in this paper is shown in Fig. $1, b$.

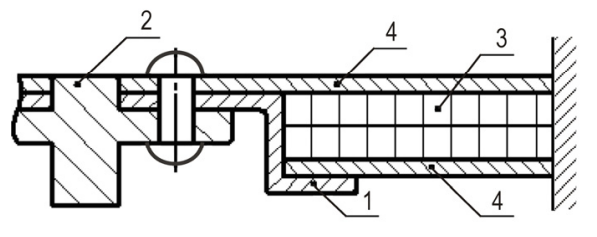

$a$

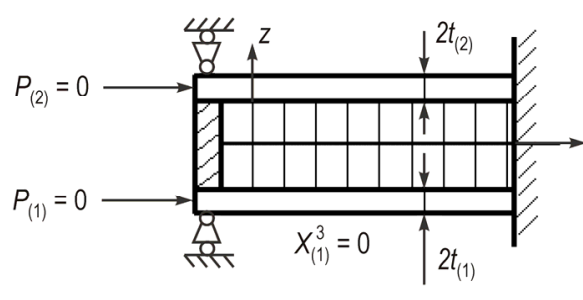

$b$

Fig. 1. The sandwich plate with the transversely soft core ( 1 is the diaphragm reinforcing the carrying layers; 2 is the rigid suppor element; 3 is the core; 4 are external carrying layers)
The generalized statement is formulated as a problem of search for a saddle point of a certain Lagrange functional. Upon that, the main variables are displacements of points of middle surfaces of carrying layers, and the Lagrange multipliers are tangental stresses in the core which are constant within its thickness. Properties of this functional are established (convexity, lower semicontinuity [23, 24] and coercivity [23, 24] on the basic of main variables (displacements of points of middle surfaces of carrying layers), concavity, upper semicontinuity and anti-coercivity on Lagrange multipliers). On the basis of the specified properties and with the use of overall results [23, 25, 26], the existence and uniqueness theorem was proved. In order to solve the problem, the double-layer iterative method of the Uzava type [27-33] was proposed each step of which is consigned to solution of the linear problem of the elasticity theory and finding the projection on the convex closed set. The method convergence theorem was given. On the basis of the developed software system in the Matlab environment, numerical experiments were carried out for the model problem. The results of numerical experiments were given. Analysis of the obtained results was performed.

Formerly, the problem of transversal bending of the sandwich plate with the transversely soft [22] core in case of rigid fixing with the lack of diaphragms [34-36] had been studied. It should be noted that physically nonlinear problems of the shell theory were studied in [37-43], and particularly the problems of the soft grid shell theory were studied in [44, 45]. Numerical solution of geometrically nonlinear problems and physically linear problems concerning bending of sandwich plates with the transversely soft core was given in [46-48].

\section{Statement of the Problem}

Let us assume that $a$ is the length of the plate, $2 t, 2 t_{(k)}$ are thicknesses of the core and the $k$-th carrying layer (in what follows, we assume that $k=1,2), X_{(k)}^{1}, X_{(k)}^{3}$ are components of the surface load reduced to the middle surface of the $k$-th layer, $M_{(k)}^{1}$ is the surface moment of external forces reduced to the middle surface of the $k$-th layer, $w^{(k)}$ and $u^{(k)}$ are deflections and axial displacements of points of the middle surface of the $k$-th layer, $T_{(k)}^{11}, M_{(k)}^{11}$ are membrane forces and internal bending moments in the $k$-th layer, respectively, $H_{(k)}=t+t_{(k)}$. Let us assume that $q^{1}$ is contact reactive interaction forces (tangental stresses) in the core which are constant within its thickness. We assume that in the right face section the edges of the carrier layers are clamped and there is no adhesive joint of the core with the support element, in the left face section the edges of the carrier layers of the plates are hinge supported on a completely rigid in the transverse direction diaphragms, glued with the end section of the core; load $P$ is applied to the middle surface of the first carrying layer from the left 
end, so that boundary conditions are fulfilled: $T_{(k)}^{11}(0)=P$, $w^{(k)}(0)=d^{2} w^{(k)}(0) / d x^{2}=0, \quad k=1,2, \quad d q^{1}(0) / d x=0$, $w^{(k)}(a)=d w^{(k)}(a) / d x=0, \quad u^{(k)}(a)=0, \quad k=1,2$, $q^{1}(a)=0$. Geometrically linear statement is considered: $M_{(k)}^{11}=-D_{(k)} d^{2} w^{(k)} / d x^{2}, \quad D_{(k)}=B_{(k)} t_{(k)}^{2} / 3 \quad$ is bending stiffness of the $k$-th layer; $T_{(k)}^{11}=B_{(k)} d u^{(k)} / d x$, $B_{(k)}=2 t_{(k)} E^{(k)} /\left(1-v_{12}^{(k)} v_{21}^{(k)}\right)$ is tensile-compression stiffness of the $k$-th layer, $E^{(k)}$ and $v_{12}^{(k)}, v_{21}^{(k)}$ are the Young's modulus of elasticity and Poisson ratios of the $k$-th layer material. Let us assume that $U=\left(w^{(1)}, w^{(2)}, u^{(1)}, u^{(2)}\right)$ is the displacement vector of points of carrying layer middle surfaces. In accordance with [49], let us consider the functional $L\left(U, q^{1}\right)=P\left(U, q^{1}\right)-A\left(U, q^{1}\right)-A_{q}\left(U, q^{1}\right)$, where $P\left(U, q^{1}\right)=\frac{1}{2} \int_{0}^{a}\left\{\sum_{k=1}^{2}\left[B_{(k)}\left(d u^{(k)} / d x\right)^{2}+D_{(k)}\left(d^{2} w^{(k)} / d x^{2}\right)^{2}\right]+\right.$ $\left.+c_{1}\left(q^{1}\right)^{2}+c_{2}\left(d q^{1} / d x\right)^{2}+c_{3}\left(w^{(2)}-w^{(1)}\right)^{2}\right\} d x \quad$ is potential energy of deformation, $c_{1}=2 t / G_{13}, \quad c_{2}=t^{3} /\left(3 E_{3}\right)$, $c_{3}=E_{3} /(2 t), G_{13}$ and $E_{3}$ are moduli of transverse shear and compression of the core, $A\left(U, q^{1}\right)=$ $=\int_{0}^{a} \sum_{k=1}^{2}\left[X_{(k)}^{1} u^{(k)}+X_{(k)}^{3} w^{(k)}+M_{(k)}^{1} d w^{(k)} / d x\right] d x+P u^{(1)}(0) \quad$ is work of external forces and moments, $A_{q}\left(U, q^{1}\right)=$ $=\int_{0}^{a}\left[\left(u^{(1)}-u^{(2)}\right)-\sum_{k=1}^{2} H_{(k)} d w^{(k)} / d x+c_{1} q^{1}-c_{2} d^{2} q^{1} / d x^{2}\right] q^{1} d x$ is work of unknown contact tangental stresses upon corresponding displacements. Believing that dependence between tangental stress and strain shear corresponds to the ideal elastic-plastic model, the problem will be considered subject to the constraint $\left|q^{1}\right| \leq q_{*}^{1}$, where $q_{*}^{1}$ is the set limit value of stress in the core. This condition means the prevention of the structural failure and corresponds to an account of the physical nonlinearity in the core material by the ideal elastic-plastic model.

\section{Generalized Statement of the Problem}

The functional $L$ can be conceived of as $L\left(U, q^{1}\right)=\Phi_{0}(U)-\Phi_{1}\left(U, q^{1}\right)-\Phi_{2}\left(q^{1}\right)$, where $\Phi_{0}(U)=$ $=\frac{1}{2} \int_{0}^{a} \sum_{k=1}^{2} B_{(k)}\left(d u^{(k)} / d x\right)^{2} d x+\frac{1}{2} \int_{0}^{a} \sum_{k=1}^{2} D_{(k)}\left(d^{2} w^{(k)} / d x^{2}\right)^{2} d x+$ $+\frac{c_{3}}{2} \int_{0}^{a}\left(w^{(2)}-w^{(1)}\right)^{2} d x, \quad \Phi_{1}\left(U, q^{1}\right)=\int_{0}^{a}\left[\left(u^{(1)}-u^{(2)}\right)-\right.$

$$
\begin{aligned}
& \left.-\sum_{k=1}^{2} H_{(k)} d w^{(k)} / d x\right] q^{1} d x+P u^{(1)}(0), \Phi_{2}\left(q^{1}\right)=\frac{1}{2} \int_{0}^{a}\left(c_{1}\left(q^{1}\right)^{2}+\right. \\
& \left.+c_{2}\left(d q^{1} / d x\right)^{2}\right) d x .
\end{aligned}
$$

Let us introduce the following Sobolev spaces $[25,50]$ $V_{1}=\left\{\eta \in W_{2}^{(1)}(0, a): \eta(a)=0\right\}, V_{2}=\left\{z \in W_{2}^{(2)}(0, a): z(0)=\right.$ $=0, z(a)=0, d z(a) / d x=0\}$, with scalar products $(u, \eta)_{k}=\int_{0}^{a} d^{k} u / d x^{k} d^{k} \eta / d x^{k} d x, \quad k=1,2$, let us denote $V=V_{2} \times V_{2} \times V_{1} \times V_{1}$. Let us also throw in the set $K=\left\{y \in V_{1}:|y(x)| \leq q_{*}^{1}, 0 \leq x \leq a\right\}$. By solving this problem we mean the vector function $\left(\hat{U}, \hat{q}^{1}\right) \in V \times K$ which is the solution of the saddle-point problem

$$
L\left(\hat{U}, \hat{q}^{1}\right)=\inf _{U \in V} \sup _{q^{1} \in K} L\left(U, q^{1}\right) .
$$

Let us remind that the functional $F: W \rightarrow R^{1}$ is called coercive (or anti-coercive) [23, 24], if $F(z) \rightarrow+\infty$ (or $F(z) \rightarrow-\infty$ ) at $\|z\|_{W} \rightarrow+\infty$.

The following results were obtained.

Lemma 1. Functionals $\Phi_{0}, \Phi_{2}$ are strictly convex, continuous and coercive.

Proof. In the definition of the functional $\Phi_{0}$, the first two summands are quadratic, whence it follows that they are strictly convex, continuous and coercive, moreover, $\Phi_{0}(U) \geq \alpha\|U\|_{V}^{2}, \alpha$ depends on $a, B_{(k)}, D_{(k)}$. The third summand is continuous and non-negative, its convexity results from the obvious algebraic inequality $b^{2}-d^{2} \geq 2 d(b-d)$. From all has been said, the statement of the lemma concerning the functional $\Phi_{0}$ follows. The functional $\Phi_{2}$ is also quadratic, and it means that it is strictly convex and continuous. The Sobolev embedding theorem $[25,30]$ implies that the inequality $\Phi_{2}(y) \geq \beta\|y\|_{V_{1}}^{2}, \quad \beta$ depends on $a, c_{1}, c_{2}$, i.e. the statement of the lemma is also true for the functional $\Phi_{2}$.

Lemma 2. The functional $\Phi_{1}$ is linear and continuous with respect to both arguments. The operator $C: V \rightarrow V_{1}$ determined from the formula $\left(C U, q^{1}\right)=\Phi_{1}\left(U, q^{1}\right)$ for all $U \in V, \quad q^{1} \in V_{1}$ is Lipschitz continuous with the constant $\gamma>0$ depending on input parameters of the problem.

Proof. Linearity of the functional $\Phi_{1}$ with respect to both arguments results directly from the definition. Using again the Sobolev embedding theorems [25, 30], it is easy to verify that $\left|\Phi_{1}\left(U, q^{1}\right)\right| \leq \gamma\|U\|_{V}\left\|q^{1}\right\|_{V_{1}}$, where the constant $\gamma>0$ depends on $a, H_{(k)}$. This implies, firstly, in virtue of 
the Riesz-Fisher theorem existence of the linear continuous operator $C$ determined by the relation $\left(C U, q^{1}\right)=\Phi_{1}\left(U, q^{1}\right)$ for all $U \in V, q^{1} \in V_{1}$, and secondly, satisfaction of the inequality $\left|\left(C(U-Y), q^{1}\right)\right| \leq \gamma\|U\|_{V}\left\|q^{1}\right\|_{V_{1}}$ which implies Lipschitz continuity of the operator $C$ with the constant $\gamma$.

Theorem 1. The problem (1) has a unique solution.

Proof. In virtue of lemma 1 , the functional $L\left(U, q^{1}\right)=\Phi_{0}(U)-\Phi_{1}\left(U, q^{1}\right)-\Phi_{2}\left(q^{1}\right)$ is strictly convex and lower semi-continuous with respect to $U$ and concave and upper semi-continuous with respect to $q^{1}$. In what follows, for any fixed $q^{1}=\tilde{q}^{1}$, inequality $L\left(U, \tilde{q}^{1}\right) \geq \alpha\|U\|_{V}^{2}-\gamma\|U\|_{V}\left\|\tilde{q}^{1}\right\|_{V_{1}}-\Phi_{2}\left(\tilde{q}^{1}\right)$ is satisfied which results in coercivity $L$ with respect to $U$. Finally, for any fixed $U=\tilde{U}$, the inequality $L\left(\tilde{U}, q^{1}\right) \leq \Phi_{0}(\tilde{U})+\gamma\|\tilde{U}\|_{V}\left\|q^{1}\right\|_{V_{1}}-\beta\left\|q^{1}\right\|_{V_{1}}^{2} \quad$ is $\quad$ valid which results in anti-coercivity $L$ with respect to $q^{1}$. The Sobolev embedding theorem $[25,30]$ implies that the set $K$ is convex and closed. But then, using the results [23, 25, 26], we obtain existence of a unique solution $\left(\hat{U}, \hat{q}^{1}\right) \in V \times K$ of the problem (1).

\section{Iterative Method and Numerical Experiments}

In order to build-up an approximate method of problem solution, let us calculate the Gateaux derivative $[23,26]$ of the functional $\Phi_{0}$. We have

$$
\begin{gathered}
\left(\Phi_{0}^{\prime}(U), Z\right)_{V}=\int_{0}^{a} \sum_{k=1}^{2} B_{(k)} \frac{d u^{(k)}}{d x} \frac{d \eta^{(k)}}{d x} d x+ \\
+\int_{0}^{a} \sum_{k=1}^{2} D_{(k)} \frac{d^{2} w^{(k)}}{d x^{2}} \frac{d^{2} z^{(k)}}{d x^{2}} d x+ \\
+c_{3} \int_{0}^{a}\left(w^{(2)}-w^{(1)}\right)\left(z^{(2)}-z^{(1)}\right) d x \\
U=\left(w^{(1)}, w^{(2)}, u^{(1)}, u^{(2)}\right), Z=\left(z^{(1)}, z^{(2)}, \eta^{(1)}, \eta^{(2)}\right) .
\end{gathered}
$$

It is true that:

Lemma 3. The functional $\Phi_{0}$ is Gateauxdifferentiable, its gradient $\Phi_{0}^{\prime}$ is a very monotone operator with the constant $\sigma>0$ depending on input parameters of the problem.

Proof. Taking into consideration (2), we have

$$
\begin{gathered}
\left(\Phi_{0}^{\prime}(U)-\Phi_{0}^{\prime}(Z), U-Z\right)_{V}= \\
=\int_{0}^{a} \sum_{k=1}^{2} B_{(k)}\left(d\left(u^{(k)}-\eta^{(k)}\right) / d x\right)^{2} d x+
\end{gathered}
$$

$$
\begin{aligned}
& +\int_{0}^{a} \sum_{k=1}^{2} D_{(k)}\left(d^{2}\left(w^{(k)}-z^{(k)}\right) / d x^{2}\right)^{2} d x+ \\
& +c_{3} \int_{0}^{a}\left(\left(w^{(2)}-z^{(2)}\right)-\left(w^{(1)}-z^{(1)}\right)\right)^{2} d x .
\end{aligned}
$$

The statement of the lemma results from this relation (3).

In order to solve the problem (1), let us consider the following iteration process. Let $q_{0}^{1} \in K$ be an arbitrary element. For $n=0,1, \ldots$ we will find $U_{n}$ as a solution of the linear problem of the elasticity theory $\Phi_{0}^{\prime}\left(U_{n}\right)+C^{*} q_{n}^{1}=0$, $C^{*}: V_{1} \rightarrow V$ is the operator conjugate to $C$. Then, we suppose $q_{n+1}^{1}=P_{K}\left(q_{n}^{1}-\tau\left(q_{n}^{1}-C U_{n}\right)\right)$, where $P_{K}$ is the operator of projection on the convex closed set $K, \tau>0$ is an iteration parameter. Thus, each step of the method resolves itself into solution of the linear problem of the elasticity theory and finding projection on the convex closed set $K$.

Theorem 2. Let $0<\tau<2 \sigma /(2 \sigma+\gamma)$. Then, $\left\{U_{n}\right\}_{n=0}^{+\infty}$ converges significantly to $\hat{U}$ at $n \rightarrow+\infty$.

Proof. Let $\left(\hat{U}, \hat{q}^{1}\right) \in V \times K$ be the solution of the problem (1). Using the technique specified in [28, 51, 52], the property of rigid non-stretchability [53] of the operator of projection on the convex closed set, we obtain that the following inequality is true

$$
\begin{gathered}
\left\|q_{n+1}^{1}-\hat{q}^{1}\right\|_{V_{1}}^{2} \leq\left\|q_{n+1}^{1}-\hat{q}^{1}\right\|_{V_{1}}^{2}+ \\
+\rho\left\|U_{n}-\hat{U}\right\|_{V}^{2} \leq\left\|q_{n}^{1}-\hat{q}^{1}\right\|_{V_{1}}^{2}, \\
\rho=\tau(2(1-\tau) \sigma-\tau \gamma) .
\end{gathered}
$$

Under hypothesis of the theorem we have $\rho>0$. It results from (4) that the bounded below (by zero) numerical sequence $\left\{\left\|q_{n}^{1}-\hat{q}^{1}\right\|_{V_{1}}^{2}\right\}_{n=1}^{+\infty}$ converges to a certain limit, and it means that $\left\|U_{n}-\hat{U}\right\|_{V} \rightarrow 0$ at $n \rightarrow+\infty$.

The proposed methods of problem solution were implemented numerically. The finite-difference approximation of the problem was built-up. The software system in the Matlab environment was developed, and calculations were performed for model problems both with and without physical nonlinearity. Calculations were performed with the following values of problem parameters: $a=20 \mathrm{~cm}$, $2 t=2 \mathrm{~cm}, 2 t_{(k)}=0.05 \mathrm{~cm}, E^{(k)}=133 \cdot 10^{3} \mathrm{MPa}, X_{(k)}^{1}=0$, $X_{(k)}^{3}=0, M_{(k)}^{1}=0, \quad v_{12}^{(k)}=v_{21}^{(k)}=0.3, k=1.2$, $G_{13}=25 \mathrm{MPa}, P=-100 \mathrm{kgf} / \mathrm{cm}, \quad q_{*}^{1}=1.5 \mathrm{~kg} / \mathrm{cm}^{2}$, $\tau=0.01$, number of mesh points $N=128$, initial estimate $U^{(0)}$ was set to zero. Results of calculations are given in Fig. 2-5 (physically linear case) and Fig. 6-9 (physically non-linear case). 


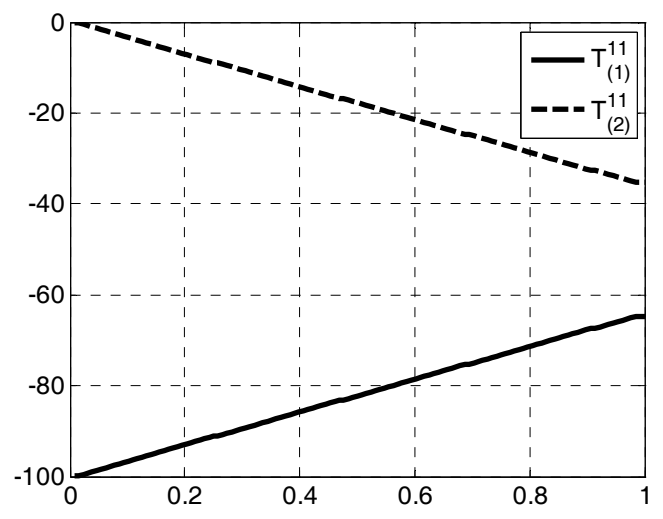

Fig. 2. Membrane forces in carrying layers

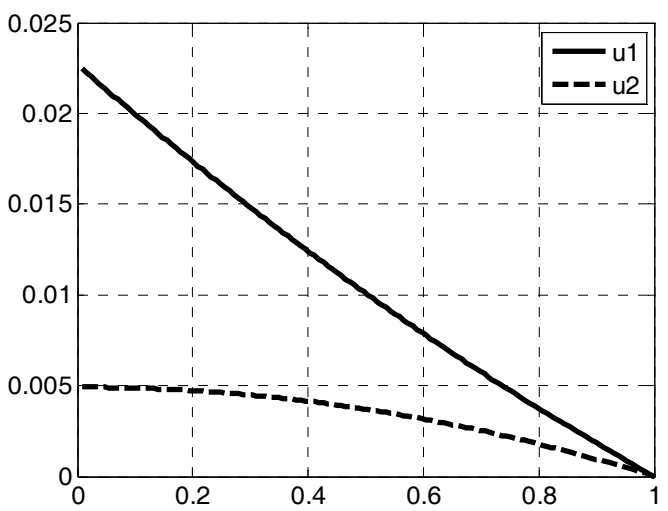

Fig. 3. Axial displacements in carrying layers

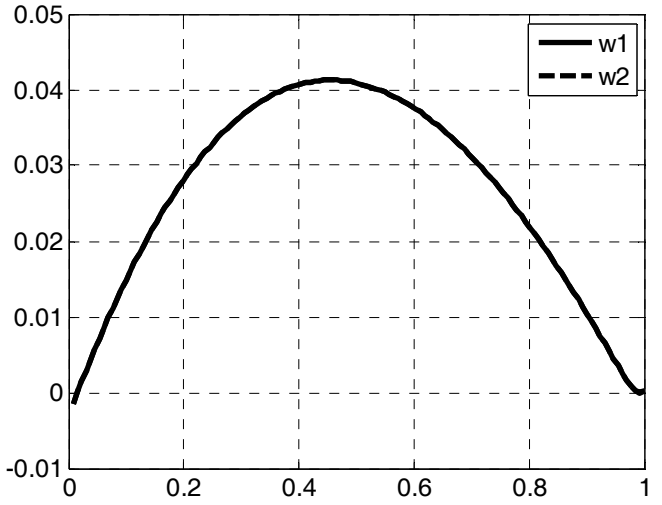

Fig. 4. Bending of carrying layers

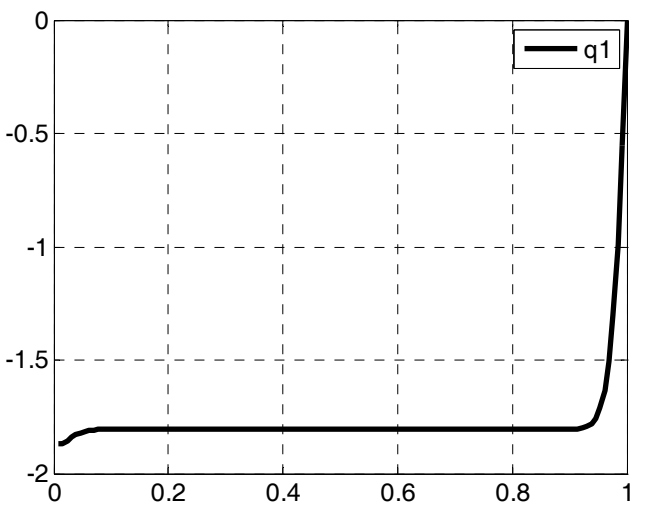

Fig. 5. Tangential stresses in the core
We should note that formulated for the function $q^{1}$ boundary conditions $d q^{1}(0) / d x=0, q^{1}(a)=0$ correspond to availability of a completely rigid in the transverse direction diaphragm in the left face section of the plate, which has adhesive joint with the core, and the lack of adhesive joint in the right face section. Fig. 5, 9 show that availability of the diaphragm ensures flow of shearing force formed in the left face section (reaction of the support) to the core with little to no stress concentrations (in case of physically linear approximation of the problem, Fig. 5), the total absence of concentration of tangential stress in the core when reaching its limit value $q_{*}^{1}=1.5 \mathrm{~kg} / \mathrm{cm}^{2}$ (Fig. 9), and the absence of adhesive joint in the right face section results in the full flow of shearing force to external layers of the structure.

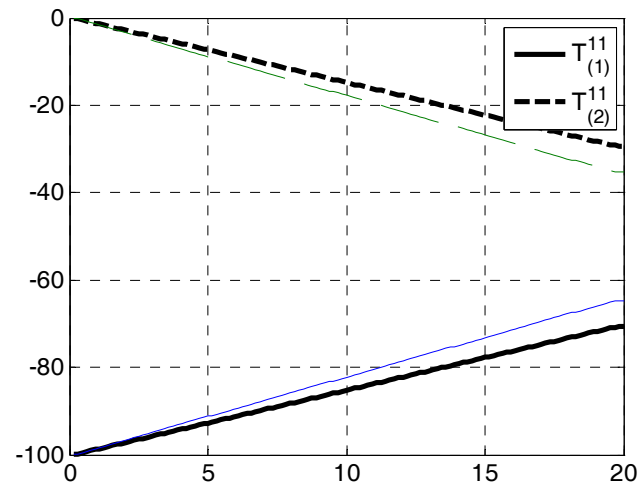

Fig. 6. Membrane forces in carrying layers

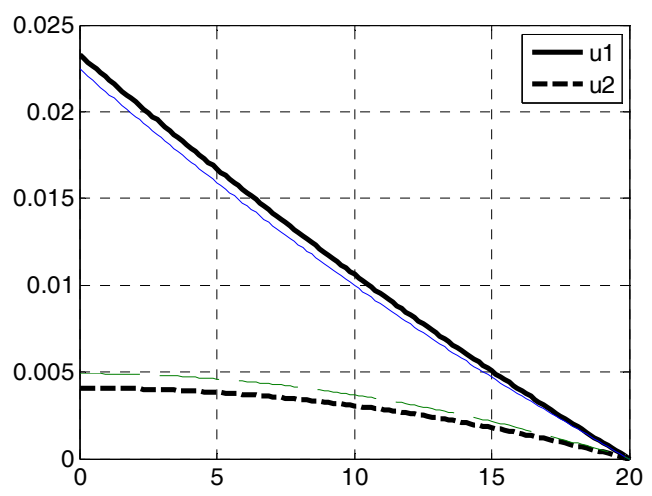

Fig. 7. Axial displacements in carrying layers

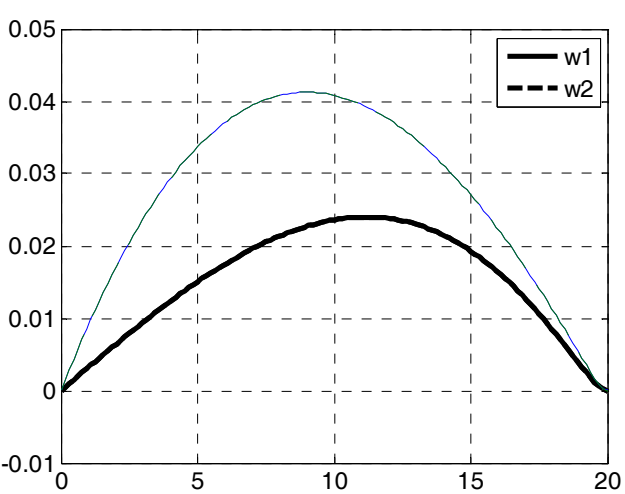

Fig. 8. Bending of carrying layers 


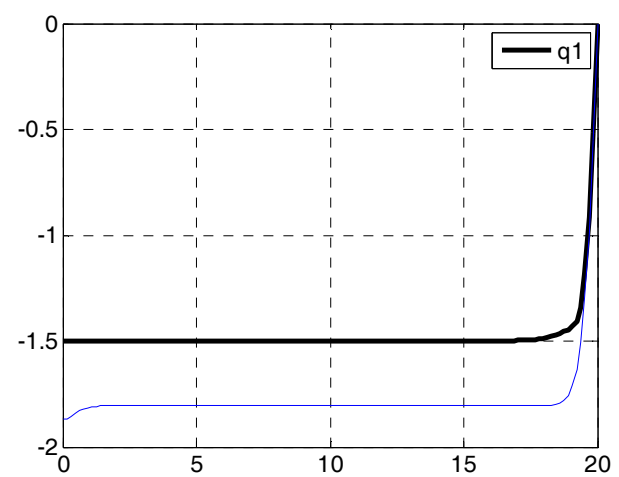

Fig. 9. Tangential stresses in the core

Publication is performed with support from the Russian Science Foundation (project 16-11-10299).

\section{References}

1. Vasil'ev V.V., Protasov V.D., Bolotin V.V. et al. Kompozitsionnye materialy: Spravochnik [Composite Materials: A Guide]. Moscow, Mashinostroenie, 512 p.

2. Öchsner A., Da Silva L.F.M., Altenbach H. Mechanics and properties of composed materials and structures. Berlin, SpringerVerlag, 2012, $195 \mathrm{p}$.

3. Vasiliev V.V., Morozov E. Advanced mechanics of composite materials and structural elements. Elsevier, 2013, 816 p.

4. Chang S-H., Parinov I., Topolov V.Y. (Eds.) Advanced materials: physics, mechanics and applications, Springer Cham Heidelberg. New York, Dordrecht, London, 2014, XVIII, 380 p.

5. Gibson R.F. Principles of composite material mechanics. Taylor\&Francis Group, LLC, 2015, 815 p.

6. Sause M.G.R. In situ monitoring of fiber-reinforced composites. Theory, basic concepts, methods, and applications. Springer International Publishing, 2016, 633 p.

7. Reissner E. Finite deflections of sandwich plates. Journal of Aeronautical Science, 1948, vol. 15, no. 7, pp. 435-440.

8. Krysin V.N. Sloistye kleenye konstruktsii v samoletostroenii [Layered laminated structure in aircraft]. Moscow, Mashinostroenie, 1980, $232 \mathrm{p}$.

9. Starovoytov E.I. Viazkouprugoplasticheskie sloistye plastiny i obolochki [Viscoelasticoplastic layered plates and shells]. Gomel Belarusian State University, 2002, 343 p.

10. Frostig Y. Elastica of sandwich panels with a transversely flexible core - A high-order theory approach. International Journal of Solids and Structures, 2009, vol. 46, pp. 2043-2059. DOI: 10.1016/j.ijsolstr.2008.05.007

11. Sukhinin S.N. Prikladnye zadachi ustoichivosti mnogosloinykh kompozitnykh obolochek [Applied problems of stability of multilayered composite shells]. Moscow, Fizmatlit, 2010, 248 p.

12. Dimitrienko Yu.I., Gubarev E.A. Yakovlev D.O. Asimptoticheskaia teoriia mnogosloinykh uprugikh plastin [The asymptotic theory of multilayer elastic plates]. Moscow: Publishing Bauman MSTU - Izdatel'stvo MGTU im. N.E. Baumana, 2014, 32 p.

13. Prokhorov B.F., Kobelev V.N. Trekhsloinye konstruktsii v sudostroenii [Three-layer construction in shipbuilding]. Leningrad, Shipbuilding - Sudostroenie, 1972, 344 p.

14. Plantema F.J. Sandwich Construction. New York, John Wiley, 1966.

15. Grigolyuk E.I., Chulkov P.P Ustojchivost i kolebaniya trekhslojnyh obolochek [Stability and Vibrations of Sandwich Shells]. Moscow, Mashinostroenie, 1973, 172 p.
16. Noor A.K., Burton W.S., Bert Ch.W. Computational models for sandwich panels and shells. Applied Mechanics Reviews, 1996, vol. 49, no. 13, pp. 155-199.

17. Hohe J., Librescu L.A Nonlinear sandwich shell theory accounting for transverse core compressibility. PAMM, the Proceedings in Applied Mathematics and Mechanics, 2003, vol. 2, pp. 158-159. DOI: 10.1002/pamm.200310064

18. Rahmani O., Lashkari M.J. Bending analysis of sandwich plates with composite face sheets and compliance functionally graded syntactic foam core. Journal of Mechanical Engineering Science, 2015, vol. 1, no. 1. pp. 1-24. DOI: 10.1177/0954406215616417

19. Badriev I.B., Makarov M.V., Paimushin V.N. On the interaction of composite plate having a vibrationabsorbing covering with incident acoustic wave. Russian Mathematics, 2015, vol. 59, no. 3, pp. 66-71. DOI: 10.3103/S1066369X1503007X

20. Liang Y., Izzuddin B.A. Large displacement analysis of sandwich plates and shells with symmetric/asymmetric lamination. Computers \& Structures, 2016, no. 1, pp. 11-32.

21. Badriev I.B., Makarov M.V., Paimushin V.N. Contact statement of mechanical problems of reinforced on a contour sandwich plates with transversally-soft core. Russian Mathematics, 2017, vol. 61, no. 1, pp. 69-75. DOI: 10.3103/S1066369X1701008X

22. Bolotin V.V., Novichkov Yu.N. Mechanics of multilayered structures. Moscow, Mashinostroenie, 1980, 375 p.

23. Ekeland I., Temam R. Convex analysis and variational problems. Amsterdam, North-Holland, 1976, 402 p.

24. Lions J.L. Quelque problèmes méthodes de résolution des problèmes aux limites nonlinéaires. Paris, Dunod, 1969, 554 p.

25. Gajewskii H., Gröger K., Zacharias K. Nichtlineare Operatorgleichungen und Operator differential gleichungen. Berlin, Akademie-Verlag, 1974, 281 p.

26. Vainberg M.M. Variatsionnyi metod i metod monotonnykh operatorov [Variational method and method of monotone operators]. Moscow, Nauka, 1972, 416 p.

27. Bank R.E., Welfert B.D., Yserentant H. A class of iterative methods for solving saddle point problems. Numerische Mathematik, 1989, vol. 56, no. 7, pp. 645-666. DOI: 10.1007/BF01405194

28. Badriev I.B., Karchevskii M.M. Convergence of the iterative Uzawa method for the solution of the stationary problem of seepage theory with a limit gradient. Journal of Soviet Mathematics, 1989, vol. 45, no. 4, pp. 1302-1309. DOI: 10.1007/bf01097083

29. Bramble J.H., Pasciak J.E., Vassilev A.T. Analysis of the inexact Uzawa algorithm for saddle point problems. SIAM Journal on Numerical Analysis, 1997, vol. 34, no. 3, pp. 1072-1092.

30. Zulehner W. Analysis of iterative methods for saddle point problems: A unified approach. Mathematics of Computation, 2002, vol. 71, no. 238, pp. 479-505. DOI: 10.1090/S0025-5718-01-01324-2

31. Gräser C., Kornhuber R. On preconditioned uzawa-type iterations for a saddle point problem with inequality constraints. Lecture Notes in Computational Science and Engineering, 2007, vol. 55, pp. 91-102.

32. Lapin A.V. Preconditioned uzawa-type methods for finitedimensional constrained saddle point problems. Lobachevskii Journal of Mathematics, 2010, vol. 31, no. 4, pp. 309-322. DOI: $10.1134 / \mathrm{s} 1995080210040013$

33. Muravleva L. Uzawa-like methods for numerical modeling of unsteady viscoplastic Bingham medium flows. Applied Numerical Mathematics, 2015, vol. 93, pp. 140-149. DOI: 10.1016/j.apnum.2014.06.001

34. Badriev I.B., Garipova G.Z., Makarov M.V., Paimushin V.N., Khabibullin R.F. Solving physically nonlinear 
equilibrium problems for sandwich plates with a transversally soft core. Lobachevskii Journal of Mathematics, 2015, vol. 36, no. 4, pp. 474-481. DOI: 10.1134/S1995080215040216

35. Badriev I.B., Banderov V.V., Garipova G.Z., Makarov M.V., Shagidullin R.R. On the solvability of geometrically nonlinear problem of sandwich plate theory. Applied Mathematical Sciences, 2015, vol. 9, no. 81-84, pp. 4095-4102.

36. Badriev I.B., Makarov M.V., Paimushin V.N. Numerical investigation of physically nonlinear problem of sandwich plate bending. Procedia Engineering, 2016, vol. 150, pp. 1050-1055. DOI: $10.1016 /$ j.proeng.2016.07.213

37. Zemskov A.V., Tarlakovskii D.V. Approximate solution of a three- dimensional problem of elastic diffusion in an orthotropic layer. Journal of Mathematical Sciences (United States), 2014, vol. 203, no. 2, pp. 221-238. DOI: 10.1007/s10958014-2103-9

38. Berezhnoi D.V., Sachenkov A.A., Sagdatullin M.K. Geometrically nonlinear deformation elastoplastic soil. Applied Mathematical Sciences, 2014, vol. 8, no. 125-128, pp. 6341-6348. DOI: 10.12988/ams.2014.48672.

39. Berezhnoi D.V., Sachenkov A.A., Sagdatullin M.K. Research of interaction of the deformable designs located in the soil. Applied Mathematical Sciences, 2014, vol. 8, no. 141-144, pp. 7107-7115. DOI: 10.12988/ams.2014.49706.

40. Abdrakhmanova A.I., Gariffulin I.R., Davydov R.L., Sultanov L.U., Fakhrutdinov L.R. Investigation of strain of solids for incompressible materials. Applied Mathematical Sciences, 2015, vol. 9, no. 118, pp. 5907-5914. DOI: 10.12988/ams.2015.57507

41. Davydov R.L., Sultanov L.U. Numerical algorithm for investigating large elasto-plastic deformations. Journal of Engineering Physics and Thermophysics, 2015, vol. 88, no. 5, pp. 1280-1288. DOI: 10.1007/s10891-015-1310-7

42. Davydov R.L., Sultanov L.U., Kharzhavina V.S. Elastoplastic model of deformation of three-dimensional bodies in terms of large strains. Global Journal of Pure and Applied Mathematics, 2015, vol. 11, no. 6, pp. 5099-5108.

43. Abdrakhmanova A.I., Sultanov L.U. Numerical modelling of deformation of hyperelastic incompressible solids. Materials Physics and Mechanics, 2016, vol. 26, no. 1, pp. 30-32.
44. Badriev I.B., Banderov V.V., Zadvornov O.A. On the equilibrium problem of a soft network shell in the presence of several point loads. Applied Mechanics and Materials, 2013, vol. 392, pp. 188-190. DOI: 10.4028/www.scientific.net/AMM.392.188

45. Badriev I.B., Banderov V.V., Zadvornov O.A. On the solving of equilibrium problem for the soft network shell with a load concentrated at the point. PNRPU Mechanics Bulletin, 2013, no. 3 , pp. 17-35.

46. Badriev I.B., Banderov V.V., Makarov M.V., Paimushin V.N. Determination of stress-strain state of geometrically nonlinear sandwich plate. Applied Mathematical Sciences, 2015, vol. 9, No. 77-80, pp. 3887-3895.

47. Badriev I.B., Garipova G.Z., Makarov M.V., Paymushin V.N. Numerical solution of the issue about geometrically nonlinear behavior of sandwich plate with transversal soft filler. Research Journal of Applied Sciences, 2015, vol. 10, no. 8, pp. 428-435. DOI: 10.3923/rjasci.2015.428.435

48. Badriev I.B., Makarov M.V., Paimushin V.N. Mathematical simulation of nonlinear problem of three-point composite sample bending test. Procedia Engineering, 2016, vol. 150, pp. 1056-1062. DOI: 10.1016/j.proeng.2016.07.214

49. Paimushin V.N., Bobrov S.N. Refined geometric nonlinear theory of sandwich shells with a transversely soft core of medium thickness for investigation of mixed buckling forms. Mechanics of Composite Materials, 2000, vol. 36, no. 1, pp. 59-66.

50. Adams R.A. Sobolev spaces. New York, San Francisco, London: Academic Press, 1975, 286 p.

51. Glowinski R., Lions J.-L., Tremolieres R. Analyse nume'rique des ine'quations variationnelles. Paris, Dunod, 1976.

52. Fortin M., Glowinski R. Augmented lagrangian methods: applications to the numerical solution of boundary-value problems. Amsterdam, North-Holland, 1983, $340 \mathrm{p}$.

53. Opial Z. Weak convergence of the sequence of successive approximations for nonexpansive mappings. Bulletin of the American Mathematical Society, 1967, vol. 73, no. 4, pp. 591-597.

54. Kinderlehrer D., Stampaccia G. An introduction to variational inequalities and their applications. New York, London, Toronto, Sydney, San Francisco, Academic Press, 1980.

Original Russian Text:

Badriev I.B., Makarov M.V., Paimushin V.N. Numerical investigation of a physically nonlinear problem of longitudinal bending of sandwich plate with transversal-soft core. PNRPU Mechanics Bulletin, 2017, no. 1, pp. 39-51. DOI: $10.15593 /$ perm.mech/2017.1.03 